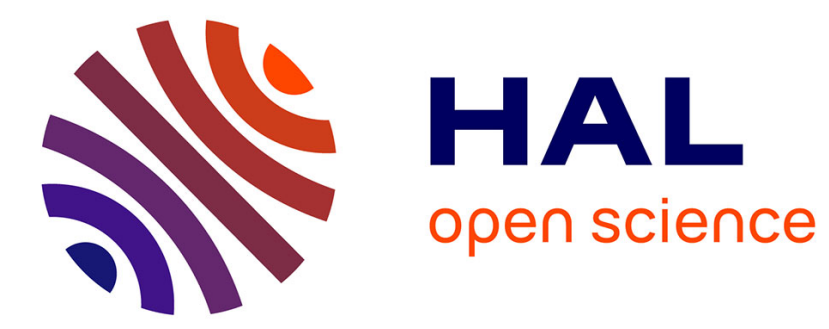

\title{
Adaptive interconnected observer for sensorless induction motor
}

\author{
Dramane Traore, J. de Léon, Alain Glumineau, Luc Loron
}

\section{To cite this version:}

Dramane Traore, J. de Léon, Alain Glumineau, Luc Loron. Adaptive interconnected observer for sensorless induction motor. International Journal of Control, 2009, 82 (9), pp.1627-1640. hal-00625725

\section{HAL Id: hal-00625725 \\ https://hal.science/hal-00625725}

Submitted on 22 Sep 2011

HAL is a multi-disciplinary open access archive for the deposit and dissemination of scientific research documents, whether they are published or not. The documents may come from teaching and research institutions in France or abroad, or from public or private research centers.
L'archive ouverte pluridisciplinaire HAL, est destinée au dépôt et à la diffusion de documents scientifiques de niveau recherche, publiés ou non, émanant des établissements d'enseignement et de recherche français ou étrangers, des laboratoires publics ou privés. 
This article was downloaded by: [Glumineau, A.]

On: 28 August 2009

Access details: Access Details: [subscription number 913197748]

Publisher Taylor \& Francis

Informa Ltd Registered in England and Wales Registered Number: 1072954 Registered office: Mortimer House, 37-41 Mortimer Street, London W1T 3JH, UK

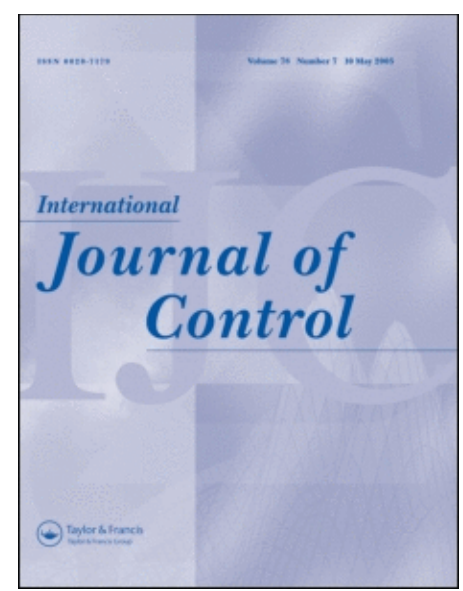

\section{International Journal of Control}

Publication details, including instructions for authors and subscription information:

http://www.informaworld.com/smpp/title content=t713393989

\section{Adaptive interconnected observer for sensorless induction motor}

D. Traore a; J. De Leon b; A. Glumineau a; L. Loron ${ }^{c}$

a IRCCyN-Institut de Recherche en Communications et Cybernétique de Nantes, Ecole Centrale de Nantes, France ${ }^{b}$ Department of Electrical Engineering, Universidad Autonoma de Nuevo Leon, San Nicolas de Los Garza, N.L, Mexico ' IREENA-Institut de Recherche en Electronique et Electrotechnique de Nantes Atlantique, Bd de l'université, 44602 Saint-Nazaire Cedex, France

First Published:September2009

To cite this Article Traore, D., De Leon, J., Glumineau, A. and Loron, L.(2009)'Adaptive interconnected observer for sensorless induction motor', International Journal of Control,82:9,1627 — 1640

To link to this Article: DOI: 10.1080/00207170802653719

URL: http://dx.doi.org/10.1080/00207170802653719

\section{PLEASE SCROLL DOWN FOR ARTICLE}

Full terms and conditions of use: http://www.informaworld.com/terms-and-conditions-of-access.pdf

This article may be used for research, teaching and private study purposes. Any substantial or systematic reproduction, re-distribution, re-selling, loan or sub-licensing, systematic supply or distribution in any form to anyone is expressly forbidden.

The publisher does not give any warranty express or implied or make any representation that the contents will be complete or accurate or up to date. The accuracy of any instructions, formulae and drug doses should be independently verified with primary sources. The publisher shall not be liable for any loss, actions, claims, proceedings, demand or costs or damages whatsoever or howsoever caused arising directly or indirectly in connection with or arising out of the use of this material. 


\title{
Adaptive interconnected observer for sensorless induction motor
}

\author{
D. Traore ${ }^{\mathrm{a} *}$, J. De Leon ${ }^{\mathrm{b}}$, A. Glumineau ${ }^{\mathrm{a}}$ and L. Loron ${ }^{\mathrm{c}}$ \\ ${ }^{a}$ IRCCyN - Institut de Recherche en Communications et Cybernétique de Nantes, Ecole Centrale de Nantes, \\ BP 92101, 1 Rue de la Noe, 44312 Nantes Cedex 3, France: ${ }^{b}$ Department of Electrical Engineering, \\ Universidad Autonoma de Nuevo Leon, P.O Box 148-F, 66450, San Nicolas de Los Garza, \\ N.L, Mexico; ${ }^{c}$ IREENA - Institut de Recherche en Electronique et Electrotechnique de \\ Nantes Atlantique, Bd de l'université, BP 406, 44602 Saint-Nazaire Cedex, France
}

(Received 26 May 2008; final version received 25 November 2008)

\begin{abstract}
An adaptive interconnected observer for induction motor (IM) drive without mechanical sensors (speed sensor and load torque sensor) is presented. The observer estimates the fluxes, the angular velocity, the load torque and the stator resistance even under or near unobservable conditions. Practical stability based on Lyapunov theory is proved to guarantee the strongly uniformly practical stability of the estimation error dynamics. A contribution of this article is the experimental validation of the observer on reference trajectories of a sensorless IM observer benchmark. The trajectories of this benchmark are chosen to test the motor near and under conditions of unobservability. Robustness with respect to parameters variations is proved and experimentally verified.
\end{abstract}

Keywords: induction motor; non-linear systems; adaptive observers; practical stability; low frequencies benchmark; sensorless

\section{Introduction}

Induction motors (IM) play an important part in many types of domestic and industrial processing machinery. The popularity of the IM is due to its ruggedness and operational reliability.

However, the IM presents a challenging control problem. This is mainly due to the following four factors:

- The IM is a complex highly coupled nonlinear system.

- The rotor fluxes and speed are not usually measurable.

- Because of heating, the rotor and stator resistances considerably vary with a significant impact on the system dynamics.

- The load torque is generally unknown.

There are various methods to control motor torque and speed, varying in complexity, performance and cost. The vector techniques are used to adjust the instantaneous values of voltage and current, thus permitting high dynamic performance. Vector control can be implemented in many different ways. The wellknown techniques are the field oriented control (FOC; Blaschke 1972) and the direct torque control (DTC; Takahashi and Noguchi 1986).

The FOC is based on resolving the instantaneous line input motor currents into two components, flux and torque, producing current components. FOC motor controllers are essentially current controller systems. In this way, it is expected that the motor will produce controllable torque similar to the separately excited DC drive. In separately excited DC drives, the torque produced is a function of the magnetic field flux linkage and armature current component and how the armature windings are connected.

For direct FOC and variable structure control (VSC) of IM drive, for example, the speed knowledge is crucial, and generally sensors are used to measure it. However, in the high-power range many sensors are used and their maintenance is difficult. Vibrations produced by the high-power motor damage the encoder coupling and the speed measure quality. Consequently, during the last decade, there has been a considerable interest to develop IM drive without mechanical sensors (sensorless). A major difficulty is the estimation of the state variables at low frequencies. Another difficulty is to ensure the robustness against parameter variations. For example, the most critical parameter affecting performance at low speed is the stator resistance (Holtz 2002; Montanari and Tilli 2006). In these papers, it is shown that relevant uncertainties in stator resistance value introduce speed and flux estimation error, leading to uncorrect speed, and flux tracking in control loop.

*Corresponding author. Email: Dramane.Traore@irccyn.ec-nantes.fr 
In the literature, several approaches have been proposed to estimate the rotor velocity, rotor fluxes and load torque from the stator current and voltage measurements such as:

- Flux estimation using rather simple models with explicit compensation of non-linearities and disturbances (Holtz and Quan 2002).

- State estimation based on high-frequency signal injection and/or saliency-induced effects on the stator voltage (Jansen and Lorenz 1995; Holtz 2000).

- Estimation using adaptive and/or robust observers based on fundamental excitation and advanced models (Kubota, Matsuse, and Nakano 1993; Montanari, Peresada, and Tilli 2003). In Kubota et al. (1993), the estimation is obtained by means of the cross product of current error vector and the observed flux vector.

- Sliding mode techniques to design observer (Tursini, Petrella, and Parasiliti 2000; Barambones and Garrido 2004).

- Cascade observer, schemes based on cascade structure of the electrical and mechanical parts of the IM (Schreier, Leon, Glumineau, and Boisliveau 2001; Ghanes, Leon, and Glumineau 2005).

- Interconnected high-gain observers in Besançon and Hammouri (1998), Ghanes, Huerta, Leon, and Glumineau (2004) and Ghanes, Leon, and Glumineau (2006).

In Ghanes et al. (2004), a high-gain observer connected to an estimator has been proposed to reconstruct flux and speed. Furthermore, in order to improve this observer design, in Ghanes et al. 2006) two interconnected observers have been used to estimate the unmeasurable variables.

In Schreier et al. (2001) and Ghanes et al. (2006), the main purpose of these observers is to estimate the state variables and the load torque by taking into account the IM observability problem at low frequency.

Canudas, Youssef, Barbot, Martin, and Malrait (2000) and Ibarra, Moreno, and Espinosa (2004) demonstrate that the main conditions to lose the observability of IM are: the excitation voltages frequency is zero and the rotor speed is constant. In Ghanes et al. (2006), to avoid the bad behaviour of observer at low frequencies (when the motor is near or under conditions of unobservability, the authors proposed the switching method based on the evaluation of the determinant of observability matrix, such that when the system is in under conditions of unobservability, the gain of the observer is turned off. Then the observer may be seen as an estimator with a limited robustness with respect to IM parameters variations. Theory of stability in the sense of Lyapunov is widely used to investigate properties of non-linear systems in real applications. It is obvious that for asymptotic stability an important feature is to know the size of the region where we can judge whether or not a given system is stable.

As for the IM, the observability properties are lost at very low speed, it is well known that it is impossible to reconstruct the state that asymptotically converges to indistinguishable trajectories (Ibarra et al. 2004). However, under these trajectories, it is possible to design an observer whose performances are acceptable even if the asymptotic stability cannot be guaranteed. Thus for these practical considerations, it is clear that we need a notion of stability that is more suitable than asymptotic stability. Such a notion is the practical stability (Laskhmikanthan, Leela, and Martynyuk 1990).

\subsection{Motivation}

In order to obtain a better performance by using a controller, it is necessary to know all parameters and measure all variables of a system. However, it is not possible to have the information of all variables of the system because this requires to implement a lot of sensors, which are so expensive or are not physical to implement in the system, or they do not exist. On the other hand, usually not all parameters are known exactly or they change on the time. For these reasons, it is necessary to estimate the non-measurable variables and identify the unknown parameters, in order to implement a control law.

The main purpose of this article is to improve the observer design proposed in Traoré, DeLeon, Glumineau, and Loron (2006) by adding an estimation of stator resistance which avoids the above-mentioned phenomenon caused by effect of stator resistance value error. The new observer is called 'adaptive interconnected observer', which preserves the basic properties of the proposed interconnected observer.

Analysing the effects of a wrong stator resistance value on the algorithm of Traoré et al. (2006), it can be noted that a steady-state estimation error arises for load torque, motor speed and flux when the IM works at very low speed (near and under unobservable conditions). Consequently, the main idea is to design an observer that can estimate the angular speed, the flux, the load torque and additionally the stator resistance (critical parameter at very low speed). A suitable and simple interconnected form of IM has been proposed including a new stator resistance estimation mechanism in the observer design when 
comparing to the previous works of Ghanes et al. (2006) and Traoré et al. (2006).

\subsection{Contribution}

In this article, we propose an interconnected adaptive observer to simultaneously estimate the flux and speed and identify the load torque and stator resistance for a sensorless IM.

The goal of the proposed interconnected adaptive observer is to combine the knowledge of the inputs (stator voltages) and the measured outputs (currents) of the sensorless IM to solve the on-line estimation of the non-measurable states (the flux and the speed), a physical parameter (stator resistance) and the load torque. Furthermore, this observer improves the observer proposed in Traoré et al. (2006) and the robustness with respect to stator resistance variation. Sufficient conditions are given to prove the practical stability of this observer. These conditions are in terms of the boundedness of parameters variations. Finally, experimental results are given, on a significant benchmark described in Ghanes et al. (2006) to illustrate the performance of the observer.

The main advantages of our adaptive observer are (i) its stability can be proved under reasonable conditions, (ii) it does not need any dynamical model of the parameters variations and (iii) the stability of the observer under or near the unobservable conditions is guaranteed, i.e. sufficient conditions are given in order to guarantee the practical stability of the sensorless IM.

\subsection{Paper structure}

This article is organised as follows. Section 2 is devoted to the model of IM. The adaptive interconnected observer design is introduced in Section 3. In Section 4, an analysis of the observer convergence using the practical stability theory is given. Experimental results are given and discussed in Section 5. Finally, some conclusions are drawn.

\section{Introduction motor model}

The IM model, described in this article, is based on the motor equations in a rotating $\mathbf{d}$ and $\mathbf{q}$-axes. ${ }^{1}$ The IM dynamics behaviour is described by

$$
\left[\begin{array}{c}
\dot{i}_{s d} \\
\dot{i}_{s q} \\
\dot{\phi}_{r d} \\
\dot{\phi}_{r q} \\
\dot{\Omega}
\end{array}\right]=\left[\begin{array}{c}
b a \phi_{r d}+b p \Omega \phi_{r q}-\gamma i_{s d}+\omega_{s} i_{s q} \\
b a \phi_{r q}-b p \Omega \phi_{r d}-\gamma i_{s q}-\omega_{s} i_{s d} \\
-a \phi_{r d}+\left(\omega_{s}-p \Omega\right) \phi_{r q}+a M_{s r} i_{s d} \\
-a \phi_{r q}-\left(\omega_{s}-p \Omega\right) \phi_{r d}+a M_{s r} i_{s q} \\
m\left(\phi_{r d} i_{s q}-\phi_{r q} i_{s d}\right)-c \Omega-\frac{1}{J} T_{l}
\end{array}\right]
$$

$$
+\left[\begin{array}{cc}
m_{1} & 0 \\
0 & m_{1} \\
0 & 0 \\
0 & 0 \\
0 & 0
\end{array}\right]\left[\begin{array}{l}
u_{s d} \\
u_{s q}
\end{array}\right]
$$

where $i_{s d}, i_{s q}, \phi_{r d}, \phi_{r q}, u_{s d}, u_{s q}, \Omega, T_{l}$ and $\omega_{s}$ are the stator currents, the rotor fluxes, the stator voltage inputs, the angular speed, the load torque and the stator frequency, respectively. The subscripts $s$ and $r$ refer to the stator and rotor. The parameters $a, b, c, \gamma$, $\sigma, m$ and $m_{1}$ are defined as $a=R_{r} / L_{r}, b=M_{s r} / \sigma L_{s} L_{r}$, $c=f_{v} / J, \gamma=\frac{L_{r}^{2} R_{s}+M_{s}^{2} R_{r}}{\sigma L_{s} L_{r}^{2}}, \sigma=1-\left(M_{s r}^{2} / L_{s} L_{r}\right), m=p M_{s r} /$ $J L_{r}, m_{1}=1 / \sigma L_{s} . R_{s}^{r}$ and $R_{r}$ are the resistances. $L_{s}$ and $L_{r}$ are the self-inductances, $M_{s r}$ is the mutual inductance between the stator and rotor windings. $p$ is the number of pole-pair. $J$ is the inertia of the system (motor and load) and $f_{v}$ is the viscous damping coefficient. Let $\gamma_{1}=\gamma-m_{1} R_{s}$ which is needed in the sequel of the study.

$\rho\left(\dot{\rho}=\omega_{s}\right)$ and $\omega_{s}$ are respectively the angular position and speed of the dq-frame with respect to a fixed stator reference frame $\alpha \beta$, where the physical variables are defined. Transformed variables in (1) are given by

$$
\left[\begin{array}{l}
x_{\alpha} \\
x_{\beta}
\end{array}\right]=P(\rho)\left[\begin{array}{l}
x_{d} \\
x_{q}
\end{array}\right], \quad\left[\begin{array}{l}
x_{d} \\
x_{q}
\end{array}\right]=P(-\rho)\left[\begin{array}{l}
x_{\alpha} \\
x_{\beta}
\end{array}\right]
$$

where $P(\rho)=\left[\begin{array}{cc}\cos \rho & \sin \rho \\ -\sin \rho & \cos \rho\end{array}\right]$.

Remark 2.1: $\rho$ is the relative angle between stator and rotor, that is needed to do a transformation from natural phase currents to dq-reference frame. $\rho$ is derived from $\omega_{s}\left(\dot{\rho}=\omega_{s}\right)$. The stator frequency $\left(\omega_{s}\right)$ can be provided by considering the two cases:

- the observer is used with a control law (e.g. scalar control) which can give the stator frequency,

- the observer is used with a control law that cannot give the stator frequency, or the observer is used without controller (fault detection, diagnosis, etc.). In this case, the stator frequency must be estimated.

\section{Adaptive interconnected observers design}

It is clear that in the literature there are several contributions in adaptive observer design. For instance, in Montanari et al. (2003) an adaptive observer is proposed to estimate the non-measurable variables and to identify the rotor resistance. Sufficient conditions are given to prove the convergence of this observer. 
Combining sliding mode techniques and adaptation methods, an adaptive sliding mode observer scheme has been proposed in Furuhashi (1990).

Furthermore, in Marino (1990) sufficient and necessary conditions are given for a non-linear system to be transformable by state-space change of coordinates into a special adaptive observer form. Other contributions propose an adaptive observer to estimate the speed and flux and assuming either the load torque or the stator resistance is known.

This section displays the design of an adaptive interconnected observer (Besançon and Hammouri 1998; Besançon, Leon, and Huerta 2006) for the sensorless IM. It is assumed that load torque and stator resistance are slowly varying with respect to electric and mechanic variables. Then the dynamic behaviour of these two variables can be read as

$$
\dot{T}_{l}=0 \quad \dot{R}_{s}=0 .
$$

Remark 3.1: Equation (2) means that the load torque and stator resistance values are assumed to be approximate by piecewise constant function. Only the bound of the load torque is assumed to be known. Furthermore, it is clear that the stator resistance slowly changes with the temperature. However, using step constant functions this variation can be approximated and the proposed approach works. Other approaches can be used, for instance singular perturbation methodology; however, the dynamics of the IM is fast with respect to the variations of the stator resistance that it could be considered constant.

Thus, the extended IM model (1) and (2) may be seen as the interconnection between two subsystems

$$
\Sigma_{1}\left\{\begin{array}{l}
\dot{X}_{1}=A_{1}\left(X_{2}, y\right) X_{1}+g_{1}\left(u, y, X_{2}, X_{1}\right)+\Phi T_{l} \\
y_{1}=C_{1} X_{1}
\end{array}\right.
$$

and

$$
\Sigma_{2}\left\{\begin{array}{l}
\dot{X}_{2}=A_{2}\left(X_{1}\right) X_{2}+g_{2}\left(u, y, X_{1}, X_{2}\right) \\
y_{2}=C_{2} X_{2}
\end{array}\right.
$$

with

$$
\begin{aligned}
A_{1}(\cdot)= & {\left[\begin{array}{ccc}
0 & b p \phi_{r q} & -m_{1} i_{s d} \\
-m \phi_{r q} & -c & 0 \\
0 & 0 & 0
\end{array}\right], } \\
A_{2}(\cdot)= & {\left[\begin{array}{ccc}
-\gamma_{1} & -b p \Omega & a b \\
0 & -a & -p \Omega \\
0 & p \Omega & -a
\end{array}\right] }
\end{aligned}
$$

$$
\begin{aligned}
& g_{1}(\cdot)= {\left[\begin{array}{c}
-\gamma_{1} i_{s d}+a b \phi_{r d}+m_{1} u_{s d}+\omega_{s} i_{s q} \\
m \phi_{r d} i_{s q} \\
0
\end{array}\right], } \\
& g_{2}(\cdot)=\left[\begin{array}{c}
-m_{1} R_{s} i_{s q}-\omega_{s} i_{s d}+m_{1} u_{s q} \\
\omega_{s} \phi_{r q}+a M_{s r} i_{s d} \\
-\omega_{s} \phi_{r d}+a M_{s r} i_{s q}
\end{array}\right], \\
& \Phi=\left[\begin{array}{c}
0 \\
-\frac{1}{J} \\
0
\end{array}\right], \\
& C_{1}=C_{2}=\left[\begin{array}{lll}
1 & 0 & 0
\end{array}\right] .
\end{aligned}
$$

$X_{1}=\left[\begin{array}{lll}i_{s d} & \Omega R_{s}\end{array}\right]^{T}$ and $X_{2}=\left[i_{s q} \phi_{r d} \phi_{r q}\right]^{T}$ are respectively the state vectors of (3) and (4), $u=\left[\begin{array}{ll}u_{s d} & u_{s q}\end{array}\right]^{T}$ is the input, and $y=\left[i_{s d} i_{s q}\right]^{T}$ is the output of the IM model. Furthermore, the IM physical operation domain $\mathcal{D}$ is defined by the set of values

$$
\begin{gathered}
\mathcal{D}=\left\{X \in R^{7}|| \phi_{r d}\left|\leq \Phi_{d}^{\max },\right| \phi_{r q} \mid \leq \Phi_{q}^{\max },\right. \\
i_{s d}\left|\leq I_{d}^{\max },\right| i_{s q}\left|\leq I_{q}^{\max },\right| \Omega \mid \leq \Omega^{\max }, \\
\left.\left|T_{l}\right| \leq T_{l}^{\max },\left|R_{s}\right| \leq R_{s}^{\max }\right\}
\end{gathered}
$$

with $X=\left[\begin{array}{lllllll}\phi_{r d} & \phi_{r q} & i_{s d} & i_{s q} & \Omega & T_{l} & R_{s}\end{array}\right]^{T}$ and $\Phi_{d}^{\max }, \Phi_{q}^{\max }, I_{d}^{\max }, I_{q}^{\max }, \Omega^{\max }, T_{l}^{\max }, R_{s}^{\max }$ the actual maximum values for fluxes, currents, speed, torque load and stator resistance, respectively.

Remark 3.2: The choice of the variables of each subsystem has been considered in order to separate the mechanical variables $\left(\Omega, T_{l}, R_{s}\right)$ from the magnetic variables $\left(\phi_{r d}, \phi_{r q}\right)$. It is clear that other choice could be considered in order to represent these subsystems, provided an observer could be designed.

The adaptive interconnected observer, developed in the sequel for the sensorless IM, is based on the interconnection between several observers satisfying some required properties, in particular the property of input persistence (Besançon and Hammouri 1996). As defined in this latter reference, the input persistence is related to the observability properties of system (3) and (4).

In order to design an observer for system (3) and (4), a separate synthesis of the observer for each subsystem is required.

\section{Remark 3.3:}

(1) $X_{2}$ and $X_{1}$ are respectively considered as inputs for subsystems $\left(\Sigma_{1}\right)$ and $\left(\Sigma_{2}\right)$. From Besançon and Hammouri (1996), solutions of $\dot{S}_{1}$ and $\dot{S}_{2}$ (used below for the observer design) are symmetric positive definite matrices.

(2) When the IM remains in the observable area, $X_{2}$ and $X_{1}$ satisfy the regularly persistence 
condition: then, asymptotic stability of the observer is guaranteed.

(3) When the IM remains in the unobservable area, $X_{2}$ and $X_{1}$ do not satisfy the regularly persistence condition. Then, asymptotic stability of the observer is not guaranteed. This problem is solved, by using the practical stability introduced in Section 4.

Remark 3.4: From (3) and (4), it is clear that $A_{1}\left(X_{2}, y\right)$ is globally Lipschitz w.r.t. $X_{2}, A_{2}\left(X_{1}\right)$ is globally Lipschitz w.r.t. $X_{1} \cdot g_{1}\left(u, y, X_{2}, X_{1}\right)$ is globally Lipschitz w.r.t. $X_{2}, X_{1}$ and uniformly w.r.t. $(u, y)$ and that $g_{2}\left(u, y, X_{2}, X_{1}\right)$ is globally Lipschitz w.r.t. $X_{2}, X_{1}$ and uniformly w.r.t. $(u, y)$.

Then, adaptive interconnected observers for subsystems (3) and (4) are given by

$$
O_{1}:\left\{\begin{aligned}
\dot{Z}_{1}= & A_{1}\left(Z_{2}, y\right) Z_{1}+g_{1}\left(u, y, Z_{2}, Z_{1}\right)+\Phi \hat{T}_{l} \\
& +\left(\varpi \Lambda S_{3}^{-1} \Lambda^{T} C_{1}^{T}+\Gamma S_{1}^{-1} C_{1}^{T}\right)\left(y_{1}-\hat{y}_{1}\right) \\
& +K C_{2}^{T}\left(y_{2}-\hat{y}_{2}\right) \\
\dot{\hat{T}}_{l}= & \varpi S_{3}^{-1} \Lambda^{T} C_{1}^{T}\left(y_{1}-\hat{y}_{1}\right) \\
& +B_{1}\left(Z_{2}\right)\left(y_{2}-\hat{y}_{2}\right)+B_{2}\left(Z_{2}\right)\left(y_{1}-\hat{y}_{1}\right) \\
\dot{S}_{1}= & -\theta_{1} S_{1}-A_{1}^{T}\left(Z_{2}, y\right) S_{1}-S_{1} A_{1}\left(Z_{2}, y\right)+C_{1}^{T} C_{1} \\
\dot{S}_{3}= & -\theta_{3} S_{3}+\Lambda^{T} C_{1}^{T} C_{1} \Lambda \\
\dot{\Lambda}= & \left(A_{1}\left(Z_{2}, y\right)-\Gamma S_{1}^{-1} C_{1}^{T} C_{1}\right) \Lambda+\Phi \\
\hat{y}_{1}= & C_{1} Z_{1}
\end{aligned}\right.
$$

$O_{2}:\left\{\begin{array}{l}\dot{Z}_{2}=A_{2}\left(Z_{1}\right) Z_{2}+g_{2}\left(u, y, Z_{1}, Z_{2}\right)+S_{2}^{-1} C_{2}^{T}\left(y_{2}-\hat{y}_{2}\right) \\ \dot{S}_{2}=-\theta_{2} S_{2}-A_{2}^{T}\left(Z_{1}\right) S_{2}-S_{2} A_{2}\left(Z_{1}\right)+C_{2}^{T} C_{2} \\ \hat{y}_{2}=C_{2} Z_{2}\end{array}\right.$

with $Z_{1}=\left[\begin{array}{lll}\hat{i}_{s d} & \hat{\Omega} & \hat{R}_{s}\end{array}\right]^{T}$ and $Z_{2}=\left[\hat{i}_{s q} \hat{\phi}_{r d} \hat{\phi}_{r q}\right]^{T}$ are the estimated state variables respectively of $X_{1}$ and $X_{2} . \theta_{1}$, $\theta_{2}, \theta_{3}$ are positive constants, $S_{1}$ and $S_{2}$ are symmetric positive definite matrices (Besançon and Hammouri 1996), $S_{3}(0)>0, B_{1}\left(Z_{2}\right)=k m \hat{\phi}_{r d}, B_{2}\left(Z_{2}\right)=-k m \hat{\phi}_{r q}$,

$$
K=\left[\begin{array}{ccc}
-k_{c 1} & 0 & 0 \\
-k_{c 2} & 0 & 0 \\
0 & 0 & 0
\end{array}\right], \quad \Gamma=\left[\begin{array}{ccc}
1 & 0 & 0 \\
0 & 1 & 0 \\
0 & 0 & \alpha
\end{array}\right]
$$

with $k, k_{c 1}, k_{c 2}, \alpha$ and $\varpi$ are positive constants.

We can see that the first observer (5) is constituted of two parts: one part to estimate the state $\left(i_{s d} \Omega R_{s}\right)$ and the second part to estimate the load torque $\left(T_{l}\right)$, by using the stator currents $i_{s d}$ and $i_{s q}$. This second part depends on a differential equation representing a dynamical system described in terms of $\Lambda$ (the state of this system) and $\Phi$ (the input matrix).
Furthermore, $\left(\varpi \Lambda S_{3}^{-1} \Lambda^{T} C_{1}^{T}+\Gamma S_{1}^{-1} C_{1}^{T}\right)$ and $K C_{2}^{T}$ are the gains of observer (5) and $S_{2}^{-1} C_{2}^{T}$ is the gain of observer (6).

The gain of the observer (5) is split into two terms. The first one, $\left(\Gamma S_{1}^{-1} C_{1}^{T}\right)$, is associated to the state estimation and depends on the solution of a Ricatti equation. The second one $\left(\varpi \Lambda S_{3}^{-1} \Lambda^{T} C_{1}^{T}\right)$ is related to the identification parameter and depends on the solution of a differential equation. The solutions of these equations are dependent of the regularly persistence (richness of the signal) with respect to state and the parameter, respectively.

Remark 3.5: In Equation (5) the term $\left(B_{1}\left(Z_{2}\right)\left(y_{2}-\hat{y}_{2}\right)+B_{2}\left(Z_{2}\right)\left(y_{1}-\hat{y}_{1}\right)\right)$ can be expressed as follows:

$$
\begin{aligned}
& B_{1}\left(Z_{2}\right)\left(y_{2}-\hat{y}_{2}\right)+B_{2}\left(Z_{2}\right)\left(y_{1}-\hat{y}_{1}\right) \\
& \quad \equiv k\left[m\left(\hat{\phi}_{r d} i_{s q}-\hat{\phi}_{r q} i_{s d}\right)-m\left(\hat{\phi}_{r d} \hat{i}_{s q}-\hat{\phi}_{r q} \hat{i}_{s d}\right)\right] \\
& \quad \equiv k\left(T_{e}-\tilde{T}_{e}\right)
\end{aligned}
$$

where $T_{e}$ and $\tilde{T}_{e}$ are the 'measured' and 'estimated' electromagnetic torques, respectively.

Lemma 3.6 (Besançon and Hammouri 1996): Assume that $v$ is a regularly persistent input for state affine system (3) and (4), and consider the following Lyapunov differential equation:

$$
\dot{S}(t)=-\theta S(t)-A^{T}(v(t)) S(t)-S(t) A(v(t))+C^{T} C
$$

with $S(0)>0$, then

$$
\begin{gathered}
\exists \theta_{0}>0, \quad \forall \theta \geq \theta_{0}, \quad \exists \bar{\alpha}>0, \quad \bar{\beta}>0, \quad t_{0}>0: \\
\forall t \geq t_{0}, \quad \bar{\alpha} I \leq S(t) \leq \bar{\beta} I,
\end{gathered}
$$

where $I$ is the identity matrix (see the proof in Besançon and Hammouri (1996)).

It is clear that $v=\left(u, X_{2}\right)$ and $S(t)=S_{1}$ for subsystem (3), and for subsystem (4) one has $v=\left(u, X_{1}\right)$ and $S(t)=S_{2}$.

It is worth mentioning that the conditions of observability loss have been stated in Ibarra et al. (2004), where the IM is unobservable under some inputs (the rotor speed constant and stator frequency set to zero simultaneously). In the IM observability area, the inputs $v=\left(u, X_{2}\right)$ and $v=\left(u, X_{1}\right)$, for subsystem (3) and (4), respectively, are regularly persistent and the convergence of the observer can be assured. However, in the unobservable region IM (under the conditions of speed constant and stator frequency set to zero), such inputs are 'bad input' and the observer convergence is not guaranteed. The use of practical stability properties can solve this problem. 


\section{Stability analysis of observer under uncertain parameters}

Under indistinguishable trajectories (unobservable area) (Ibarra et al. 2004), the asymptotic convergence of any observer cannot always be guaranteed because the observability properties are lost on these trajectories. Then, in such cases, it is necessary to analyse the stability of the observer and the closed loop system. The practical stability notion (Laskhmikanthan et al. 1990) allows to establish that dynamics of the estimation error converge in a ball $B_{r}$ of radius $r$ $\left(x \in B_{r} \Rightarrow\|x\| \leq r\right)$. If $r \rightarrow 0$ at $t \rightarrow \infty$, then the classical asymptotic stability is obtained.

\subsection{Preliminary results}

This part is essentially devoted to introduce some concepts and results of practical stability properties using Lyapunov-like functions and the theory of differential inequalities (Laskhmikanthan et al. 1990). Define the following class of function: $\mathbf{W}=\left\{d_{1} \in\right.$ $C\left[\mathbb{R}_{+}, \mathbb{R}_{+}\right]: \quad d_{1}(l)$ is strictly increasing in $l$ and $d_{1}(l) \rightarrow \infty$ as $\left.l \rightarrow \infty\right\}$. Let $B_{r}=\left\{e \in \mathbb{R}^{n}:\|e\| \leq r\right\}$ where $e=\left(\epsilon_{i}, i=1, \ldots, n\right)^{T}$.

Consider the dynamical system

$$
\dot{e}=f(t, e), \quad e\left(t_{0}\right)=e_{0}, \quad t_{0} \geq 0 .
$$

Then system (7) is said to be:

(PS1) Uniformly practical stable if, given $\left(\hbar_{1}, \hbar_{2}\right)$ with $0<\hbar_{1}<\hbar_{2}$, we have

$$
\left\|e_{0}\right\| \leq \hbar_{1} \Rightarrow\|e(t)\| \leq \hbar_{2}, \quad \forall t \geq t_{0}, \quad \forall t_{0} \in \mathbb{R}_{+} .
$$

(PS2) Uniformly practical quasi-stable if, given $\hbar_{1}>0$, $\mathfrak{\Im}>0, T>0$ and $\forall t_{0} \in \mathbb{R}_{+}$, we have

$$
\left\|e_{0}\right\| \leq \hbar_{1} \Rightarrow\|e(t)\| \leq \mathfrak{I}, \quad t \geq t_{0}+T .
$$

(PS3) Strongly uniformly practical stable, if (PS1) and (PS2) hold together.

Theorem 4.1 (Laskhmikanthan et al. 1990): Assume that:

(i) $\hbar_{1}, \hbar_{2}$ are given such that $0<\hbar_{1}<\hbar_{2}$;

(ii) $V \in C\left[\mathbb{R}_{+} \times \mathbb{R}^{n}, \mathbb{R}_{+}\right]$and $V(t, e)$ is locally Lipschitzian in $e$;

(iii) for $(t, e) \in \mathbb{R}_{+} \times B_{\hbar_{2}}, d_{1}(\|e\|) \leq V(t, e) \leq d_{2}(\|e\|)$ and

$$
\dot{V}(t, e) \leq \wp(t, V(t, e))
$$

where $d_{1}, d_{2} \in \mathbf{W}$ and $\wp \in C\left[\mathbb{R}_{+}^{2}, \mathbb{R}\right]$;

(iv) $d_{2}\left(\hbar_{1}\right)<d_{1}\left(\hbar_{2}\right)$ holds.
Then, the practical stability properties of:

$$
\dot{l}=\wp(t, l), \quad l\left(t_{0}\right)=l_{0} \geq 0,
$$

imply the corresponding practical stability properties of system (7).

Corollary 4.2 (Laskhmikanthan et al. 1990): In Theorem 4.1, $\wp(t, l)=-\alpha_{1} l+\alpha_{2}$, with $\alpha_{1}$ and $\alpha_{2}>0$, implies strong uniform practical stability of system (7).

For the proofs of Theorem 4.1 and Corollary 4.2, we refer to Laskhmikanthan et al. (1990).

\subsection{Stability analysis}

Consider that the IM parameters are uncertain bounded with well-known nominal values. Then, Equations (3) and (4) can be rewritten as

$$
\begin{gathered}
\dot{X}_{1}=A_{1}\left(X_{2}, y\right) X_{1}+g_{1}\left(u, y, X_{2}, X_{1}\right)+\Phi T_{l} \\
+\Delta A_{1}\left(X_{2}, y\right)+\Delta g_{1}\left(u, y, X_{2}, X_{1}\right) \\
y_{1}=C_{1} X_{1} \\
\dot{X}_{2}=A_{2}\left(X_{1}\right) X_{2}+g_{2}\left(u, y, X_{1}, X_{2}\right) \\
\quad+\Delta A_{2}\left(X_{1}\right)+\Delta g_{2}\left(u, y, X_{1}, X_{2}\right) \\
y_{2}=C_{2} X_{2}
\end{gathered}
$$

with $\Delta A_{1}\left(X_{2}, y\right), \quad \Delta A_{2}\left(X_{1}\right), \quad \Delta g_{1}\left(u, y, X_{2}, X_{1}\right) \quad$ and $\Delta g_{2}\left(u, y, X_{1}, X_{2}\right)$ are the uncertain terms of $A_{1}\left(X_{2}, y\right)$, $A_{2}\left(X_{1}\right), g_{1}\left(u, y, X_{2}, X_{1}\right), \quad g_{2}\left(u, y, X_{1}, X_{2}\right)$, respectively. Note that $R_{r}^{i d}, R_{s}^{i d}, M_{s r}^{i d}, J^{i d}, L_{s}^{i d}$ and $L_{r}^{i d}$ are the identified parameters. Because of experimental conditions (e.g. temperature variation, imprecision of identification method), the identified parameters are not exactly the real parameters of the IM. Then, one has $b=b^{i d}+\Delta b, a=a^{i d}+\Delta a, c=c^{i d}+\Delta c, m=m^{i d}+$ $\Delta m, m_{1}=m_{1}^{i d}+\Delta m_{1}, \gamma_{1}=\gamma_{1}^{i d}+\Delta \gamma_{1}$, with $b^{i d}, a^{i d}, c^{i d}$, $m^{i d}, m_{1}^{i d}, \gamma_{1}^{i d}, \Delta b, \Delta a, \Delta c, \Delta m, \Delta m_{1}$ and $\Delta \gamma_{1}$ are the identified values and uncertain values for $b, a, c, m, m_{1}$ and $\gamma_{1}$, respectively. It follows that the uncertain terms are represented as

$$
\begin{gathered}
\Delta A_{1}(\cdot)=\left[\begin{array}{ccc}
0 & \Delta b \cdot p \phi_{r q} & -\Delta m_{1} \cdot i_{s d} \\
-\Delta m \cdot \phi_{r q} & -\Delta c & 0 \\
0 & 0 & 0
\end{array}\right] \\
\Delta g_{1}(\cdot)=\left[\begin{array}{c}
-\Delta \gamma_{1} \cdot i_{s d}+\Delta a b \cdot \phi_{r d}+\Delta m_{1} \cdot u_{s d}+\omega_{s} i_{s q} \\
\Delta m \cdot \phi_{r d} i_{s q} \\
0
\end{array}\right] .
\end{gathered}
$$

$\Delta A_{2}\left(X_{1}\right), \Delta g_{2}\left(u, y, X_{2}, X_{1}\right)$ can be written following a similar way. 
By considering the IM physical operation domain $\mathcal{D}$, then there exist positive constants $\rho_{i}>0$, for $i=1, \ldots, 4$; such that

$$
\left\|\Delta A_{1}\left(X_{2}, y\right)\right\| \leq \rho_{1}, \quad\left\|\Delta A_{2}\left(X_{1}\right)\right\| \leq \rho_{2},
$$

$\left\|\Delta g_{1}\left(u, y, X_{2}, X_{1}\right)\right\| \leq \rho_{3}, \quad\left\|\Delta g_{2}\left(u, y, X_{1}, X_{2}\right)\right\| \leq \rho_{4}$.

The parameters $\rho_{i}, i=1, \ldots, 4$ are positive constants determined from the maximal values of $\Delta A_{1}(\cdot), \Delta A_{2}(\cdot)$, $\Delta g_{1}(\cdot)$ and $\Delta g_{2}(\cdot)$ in the physical domain $\mathcal{D}$.

Let the estimation errors define as

$$
\epsilon_{1}^{\prime}=X_{1}-Z_{1}, \quad \epsilon_{2}=X_{2}-Z_{2}, \quad \epsilon_{3}=T_{l}-\hat{T}_{l} .
$$

From Equations (5) and (6) and (10) and (11), one gets

$$
\begin{aligned}
\dot{\epsilon}_{1}^{\prime}= & {\left[A_{1}\left(Z_{2}, y\right)-\varpi \Lambda S_{3}^{-1} \Lambda^{T} C_{1}^{T} C_{1}-\Gamma S_{1}^{-1} C_{1}^{T} C_{1}\right] \epsilon_{1}^{\prime} } \\
& +\Phi \epsilon_{3}-K C_{2}^{T} C_{2} \epsilon_{2}+\left[A_{1}\left(X_{2}, y\right)+\Delta A_{1}\left(X_{2}, y\right)\right. \\
& \left.-A_{1}\left(Z_{2}, y\right)\right] X_{1}+g_{1}\left(u, y, X_{2}, X_{1}\right) \\
& +\Delta g_{1}\left(u, y, X_{2}, X_{1}\right)-g_{1}\left(u, y, Z_{2}, Z_{1}\right)
\end{aligned}
$$$$
\dot{\epsilon_{2}}=\left[A_{2}\left(Z_{1}\right)-S_{2}^{-1} C_{2}^{T} C_{2}\right] \epsilon_{2}+\left[A_{2}\left(X_{1}, y\right)\right.
$$$$
\left.+\Delta A_{2}\left(X_{1}, y\right)-A_{2}\left(Z_{1}, y\right)\right] X_{2}+g_{2}\left(u, y, X_{1}, X_{2}\right)
$$$$
+\Delta g_{2}\left(u, y, X_{1}, X_{2}\right)-g_{2}\left(u, y, Z_{1}, Z_{2}\right)
$$

$$
\dot{\epsilon}_{3}=-\varpi S_{3}^{-1} \Lambda^{T} C_{1}^{T} C_{1} \epsilon_{1}^{\prime}-B_{1}\left(Z_{2}\right) C_{2} \epsilon_{2}-B_{2}\left(Z_{2}\right) C_{1} \epsilon_{1}^{\prime}
$$

Following the same idea as in Zhang (2002), and applying the transformation $\epsilon_{1}=\epsilon_{1}^{\prime}-\Lambda \epsilon_{3}$, it yields

$$
\dot{\epsilon}_{1}=\dot{\epsilon}_{1}^{\prime}-\Lambda \dot{\epsilon}_{3}-\dot{\Lambda} \epsilon_{3}
$$

By substituting (16) into (13)-(15), the estimation error dynamics are given by

$$
\begin{aligned}
\dot{\epsilon}_{1}= & {\left[A_{1}\left(Z_{2}, y\right)-\Gamma S_{1}^{-1} C_{1}^{T} C_{1}+B_{21}\right] \epsilon_{1} } \\
& +g_{1}\left(u, y, X_{2}, X_{1}\right)+\Delta g_{1}\left(u, y, X_{2}, X_{1}\right) \\
& -g_{1}\left(u, y, Z_{2}, Z_{1}\right)+\left(B_{12}-K^{\prime}\right) \epsilon_{2}+B_{22} \epsilon_{3} \\
& +\left[A_{1}\left(X_{2}, y\right)+\Delta A_{1}\left(X_{2}, y\right)-A_{1}\left(Z_{2}, y\right)\right] X_{1} \\
\dot{\epsilon}_{2}= & {\left[A_{2}\left(Z_{1}\right)-S_{2}^{-1} C_{2}^{T} C_{2}\right] \epsilon_{2}+\left[A_{2}\left(X_{1}\right)\right.} \\
& \left.+\Delta A_{2}\left(X_{1}\right)-A_{2}\left(Z_{1}\right)\right] X_{2} g_{2}\left(u, y, X_{1}, X_{2}\right) \\
& -g_{2}\left(u, y, Z_{1}, Z_{2}\right)+\Delta g_{2}\left(u, y, X_{1}, X_{2}\right) \\
\dot{\epsilon}_{3}= & -\left[\varpi S_{3}^{-1} \Lambda^{T} C_{1}^{T} C_{1} \Lambda+B_{2}^{\prime}\right] \epsilon_{3} \\
& -\left[\varpi S_{3}^{-1} \Lambda^{T} C_{1}^{T} C_{1}+B_{2}^{\prime \prime}\right] \epsilon_{1}-B_{1}^{\prime} \epsilon_{2}
\end{aligned}
$$

with $B_{21}=\Lambda B_{2}\left(Z_{2}\right) C_{1}, B_{12}=\Lambda B_{1}\left(Z_{2}\right) C_{2}, B_{22}=\Lambda B_{2} \times$ $\left(Z_{2}\right) C_{1} \Lambda, B_{2}{ }^{\prime}=B_{2}\left(Z_{2}\right) C_{1} \Lambda, B_{2}{ }^{\prime \prime}=B_{2}\left(Z_{2}\right) C_{1}, B_{1}{ }^{\prime}=B_{1} \times$ $\left(Z_{2}\right) C_{2}, K^{\prime}=K C_{2}^{T} C_{2}$. Since $\left(u, X_{2}\right)$ and $\left(u, X_{1}\right)$ are regular persistent inputs for subsystems (10) and (11), respectively, and from Lemma 3.6, then there exist $t_{0} \geq 0$ and real numbers $\eta_{S_{i}}^{\max }>0, \eta_{S_{i}}^{\min }>0$ which are independent of $\theta_{i}$ such that $V\left(t, \epsilon_{i}\right)=\epsilon_{i}^{T} S_{i} \epsilon_{i}(1 \leq i \leq 3)$ (Besançon and Hammouri 1996)

$$
\forall t \geq t_{0} \quad \eta_{S_{i}}^{\min }\left\|\epsilon_{i}\right\|^{2} \leq V\left(t, \epsilon_{i}\right) \leq \eta_{S_{i}}^{\max }\left\|\epsilon_{i}\right\|^{2} .
$$

Theorem 4.3: Consider the extended IM dynamic model represented by (3) and (4). Systems (5) and (6) is an adaptive observer for systems (3) and (4). Furthermore, the strongly uniformly practical stability of estimation error dynamics (17) is established.

Proof of Theorem 4.3: A Lyapunov function candidate is considered as $V_{0}=V_{1}+V_{2}+V_{3}$, where $V_{1}=$ $\epsilon_{1}^{T} S_{1} \epsilon_{1}, V_{2}=\epsilon_{2}^{T} S_{2} \epsilon_{2}$ and $V_{3}=\epsilon_{3}^{T} S_{3} \epsilon_{3}$. Taking the time derivative of $V_{0}$ and using (5), (6) and (17), we have

$$
\begin{aligned}
\dot{V}_{0}= & \epsilon_{1}^{T}\left\{-\theta_{1} S_{1}-\left(2 S_{1} \Gamma S_{1}^{-1}-1\right) C_{1}^{T} C_{1}\right. \\
& \left.+2 S_{1} B_{21}\right\} \epsilon_{1}+2 \epsilon_{1}^{T} S_{1}\left\{A_{1}\left(X_{2}, y\right)\right. \\
& \left.-A_{1}\left(Z_{2}, y\right)+\Delta A_{1}\left(X_{2}, y\right)\right\} X_{1} \\
& +2 \epsilon_{1}^{T} S_{1}\left\{g_{1}\left(u, y, X_{2}, X_{1}\right)-g_{1}\left(u, y, Z_{2}, Z_{1}\right)\right. \\
& \left.+\Delta g_{1}\left(u, y, X_{2}, X_{1}\right)\right\}+\epsilon_{3}^{T}\left[-\theta_{3} S_{3}-(2 \varpi-1) \Lambda^{T} C_{1}^{T} C_{1} \Lambda\right. \\
& \left.-2 S_{3} B_{2}^{\prime}\right] \epsilon_{3}+\epsilon_{2}^{T}\left\{-\theta_{2} S_{2}-C_{2}^{T} C_{2}\right\} \epsilon_{2} \\
& +2 \epsilon_{2}^{T} S_{2}\left\{A_{2}\left(X_{1}\right)-A_{2}\left(Z_{1}\right)+\Delta A_{2}\left(X_{1}\right)\right\} X_{2} \\
& +2 \epsilon_{2}^{T} S_{2}\left\{g_{2}\left(u, y, X_{1}, X_{2}\right)-g_{2}\left(u, y, Z_{1}, Z_{2}\right)\right. \\
& \left.+\Delta g_{2}\left(u, y, X_{1}, X_{2}\right)\right\} \\
& +2 \epsilon_{1}^{T} S_{1}\left(B_{12}-K^{\prime}\right) \epsilon_{2}+2 \epsilon_{1}^{T} S_{1} B_{22} \epsilon_{3} \\
& -2 \epsilon_{3}^{T}\left(B_{2}^{\prime \prime}+\varpi \Lambda^{T} C_{1}^{T} C_{1}\right) \epsilon_{1}-2 \epsilon_{3}^{T} S_{3} B_{1}^{\prime} \epsilon_{2} .
\end{aligned}
$$

According to Lemma 3.6 and tacking the initial conditions of the IM drive and the observer in the physical operation domain $\mathcal{D}$, the following inequalities hold:

$$
\begin{aligned}
& \left\|S_{1}\right\| \leq k_{1},\left\|S_{2}\right\| \leq k_{5},\left\|X_{1}\right\| \leq k_{3},\left\|X_{2}\right\| \leq k_{7} \\
& \left\|\left\{g_{1}\left(u, y, X_{2}, X_{1}\right)-g_{1}\left(u, y, Z_{2}, Z_{1}\right)\right\}\right\| \leq k_{4}\left\|\epsilon_{2}\right\|+k_{16}\left\|\epsilon_{1}\right\| \\
& \left\|\left\{A_{1}\left(X_{2}, y\right)-A_{1}\left(Z_{2}, y\right)\right\}\right\| \leq k_{2}\left\|\epsilon_{2}\right\| \\
& \left\|\left\{A_{2}\left(X_{1}\right)-A_{2}\left(Z_{1}\right)\right\}\right\| \leq k_{6}\left\|\epsilon_{1}\right\|+k_{20}\left\|\epsilon_{3}\right\| \\
& \left\|\left\{g_{2}\left(u, y, X_{1}, X_{2}\right)-g_{2}\left(u, y, Z_{1}, Z_{2}\right)\right\}\right\| \leq k_{8}\left\|\epsilon_{1}\right\|+k_{17}\left\|\epsilon_{2}\right\| \\
& \left\|B_{1}^{\prime}\right\| \leq k_{9},\left\|B_{2}^{\prime}\right\| \leq k_{10},\left\|B_{2}^{\prime \prime}\right\| \leq k_{18},\left\|B_{12}\right\| \leq k_{11}, \\
& \left\|B_{21}\right\| \leq k_{12},\left\|B_{22}\right\| \leq k_{13},\left\|K^{\prime}\right\| \leq k_{14} \\
& \left\|\Lambda^{T} C_{1}^{T} C_{1}\right\| \leq k_{19},\left\|S_{3}\right\| \leq k_{15} .
\end{aligned}
$$

Substituting Equation (20) into (19), from Assumption 3 and by regrouping with respect to $\left\|\epsilon_{1}\right\|,\left\|\epsilon_{2}\right\|$ and $\left\|\epsilon_{3}\right\|$, the time derivative of $V_{0}$ (19) can be rewritten as follows:

$$
\begin{aligned}
\dot{V}_{0} \leq & -\left(\theta_{1}-2 k_{12}-2 k_{1} k_{16}\right) \epsilon_{1}^{T} S_{1} \epsilon_{1} \\
& -\left(\theta_{2}-2 k_{5} k_{17}\right) \epsilon_{2}^{T} S_{2} \epsilon_{2}-\left(\theta_{3}+2 k_{10}\right) \epsilon_{3}^{T} S_{3} \epsilon_{3} \\
& +2\left(\mu_{1}+\mu_{2}+\mu_{3}+\mu_{4}+\mu_{5}\right)\left\|\epsilon_{1}\right\|\left\|\epsilon_{2}\right\| \\
& +2 \mu_{9}\left\|\epsilon_{2}\right\|\left\|\epsilon_{3}\right\|+2 \mu_{8}\left\|\epsilon_{1}\right\|\left\|\epsilon_{3}\right\| \\
& +\mu_{6}\left\|\epsilon_{1}\right\|+\mu_{7}\left\|\epsilon_{2}\right\|
\end{aligned}
$$


where $\mu_{1}=k_{1} k_{2} k_{3}, \mu_{2}=k_{1} k_{4}, \mu_{3}=k_{5} k_{6} k_{7}, \mu_{4}=k_{5} k_{8}$, $\mu_{5}=k_{1}\left(k_{11}-k_{14}\right), \quad \mu_{6}=2\left(k_{1} k_{3} \rho_{1}+k_{1} \rho_{3}\right), \quad \mu_{7}=$ $2\left(k_{5} k_{7} \rho_{2}+k_{5} \rho_{4}\right), \quad \mu_{8}=k_{1} k_{13}-\left(\varpi k_{19}+k_{18}\right), \quad \mu_{9}=$ $-k_{15} k_{9}+k_{5} k_{20} k_{7}$.

Inequality (21) can be rewritten in terms of $V_{1}, V_{2}$ and $V_{3}$ as follows:

$$
\begin{aligned}
\dot{V}_{0} \leq & -\left(\theta_{1}-2 k_{12}-2 k_{1} k_{16}\right) V_{1}-\left(\theta_{2}-2 k_{5} k_{17}\right) V_{2} \\
& -\left(\theta_{3}+2 k_{10}\right) V_{3}+2 \tilde{\mu} \sqrt{V_{1}} \sqrt{V_{2}}+\tilde{\mu}_{7} \sqrt{V_{2}} \\
& +2 \tilde{\mu}_{9} \sqrt{V_{2}} \sqrt{V_{3}}+\tilde{\mu}_{6} \sqrt{V_{1}}+2 \tilde{\mu}_{8} \sqrt{V_{1}} \sqrt{V_{3}}
\end{aligned}
$$

where $\quad \tilde{\mu}=\sum_{j=0}^{5} \tilde{\mu}_{j}, \quad \tilde{\mu}_{j}=\frac{\mu_{j}}{\sqrt{\eta_{s_{1}}^{\min }} \sqrt{\eta_{s_{2}}}}, \quad j=1, \ldots, 5$; $\tilde{\mu}_{8}=\frac{\mu_{8}}{\sqrt{\eta_{S_{1}}^{\min }} \sqrt{\eta_{S_{3}}^{\min }}}, \tilde{\mu}_{9}=\frac{\mu_{9}}{\sqrt{\eta_{S_{2}}^{\min }} \sqrt{\eta_{S_{3}}^{\min }}}, \tilde{\mu}_{6}=\frac{\mu_{6}}{\sqrt{\eta_{S_{1}}^{\min }}}, \tilde{\mu}_{7}=\frac{\mu_{7}}{\sqrt{\eta_{S_{2}}^{\min }}}$.

Using the following inequalities:

$$
\begin{aligned}
\sqrt{V_{1}} \sqrt{V_{2}} & \leq \frac{\varphi_{1}}{2} V_{1}+\frac{1}{2 \varphi_{1}} V_{2} \\
\sqrt{V_{1}} \sqrt{V_{3}} & \leq \frac{\varphi_{2}}{2} V_{1}+\frac{1}{2 \varphi_{2}} V_{3} \\
\sqrt{V_{2}} \sqrt{V_{3}} & \left.\leq \frac{\varphi_{3}}{2} V_{2}+\frac{1}{2 \varphi_{3}} V_{3} \quad \forall \varphi_{i}(i=1,2,3) \in\right] 0,1[,
\end{aligned}
$$

by substituting (23) into (22), we obtain

$$
\begin{aligned}
\dot{V}_{0} \leq & -\left(\theta_{1}-2 k_{12}-2 k_{1} k_{16}-\tilde{\mu} \varphi_{1}-\tilde{\mu}_{8} \varphi_{2}\right) V_{1} \\
& -\left(\theta_{2}-2 k_{5} k_{17}-\frac{\tilde{\mu}}{\varphi_{2}}-\tilde{\mu}_{9} \varphi_{3}\right) V_{2} \\
& -\left(\theta_{3}+2 k_{10}-\frac{\tilde{\mu}_{8}}{\varphi_{2}}-\frac{\tilde{\mu}_{9}}{\varphi_{3}}\right) V_{3} \\
& +\tilde{\mu}_{6}\left\|\epsilon_{1}\right\|+\tilde{\mu}_{7}\left\|\epsilon_{2}\right\|,
\end{aligned}
$$

and consequently, we have

$$
\begin{aligned}
\dot{V}_{0} & \leq-\delta\left(V_{1}+V_{2}+V_{3}\right)+\mu\left(\sqrt{V_{1}}+\sqrt{V_{2}}\right) \\
& \leq-\delta V_{0}+\mu \psi \sqrt{V_{0}},
\end{aligned}
$$

where $\delta=\min \left(\delta_{1}, \delta_{2}, \delta_{3}\right), \quad \mu=\max \left(\tilde{\mu}_{6}, \tilde{\mu}_{7}\right)$, where $\delta_{1}=\theta_{1}-2 k_{12}-2 k_{1} k_{16}-\tilde{\mu} \varphi_{1}-\tilde{\mu}_{8} \varphi_{2}>0, \quad \delta_{2}=\theta_{2}-$ $2 k_{5} k_{17}-\frac{\tilde{\mu}}{\varphi_{2}}-\tilde{\mu}_{9} \varphi_{3}>0, \quad \delta_{3}=\theta_{3}+2 k_{10}-\frac{\tilde{\mu}_{8}}{\varphi_{2}}-\frac{\tilde{\mu}_{9}}{\varphi_{3}}>0$, and $\psi>0$, such that $\psi \sqrt{V_{1}+V_{2}+V_{3}}>\sqrt[\varphi_{2}]{V_{1}}+\sqrt{V_{2}}$. So that

$$
\begin{aligned}
& \theta_{1}>2 k_{12}+2 k_{1} k_{16}+\tilde{\mu} \varphi_{1}+\tilde{\mu}_{8} \varphi_{2} \\
& \theta_{2}>2 k_{5} k_{17}+\frac{\tilde{\mu}}{\varphi_{2}}+\tilde{\mu}_{9} \varphi_{3} \\
& \theta_{3}>\frac{\tilde{\mu}_{8}}{\varphi_{2}}+\frac{\tilde{\mu}_{9}}{\varphi_{3}}-2 k_{10} .
\end{aligned}
$$

Next, consider the following change of variable $v=2 \sqrt{V_{0}}$, the time derivative of $v$ is given by

$$
\dot{v} \leq-\delta v+\psi \mu \text {. }
$$

From Theorem 4.1 we have $\wp(t, l)=-\delta l+\psi \mu$, therefore (9) can be expressed as

$$
\dot{l}=-\delta l+\psi \mu, \quad l\left(t_{0}\right)=l_{0} \geq 0
$$

and its solution is given as

$$
l(t)=l\left(t_{0}\right) e^{-\delta\left(t-t_{0}\right)}+r \cdot\left(1-e^{-\delta\left(t-t_{0}\right)}\right)
$$

where $r=\frac{\psi \mu}{\delta}$ depends on parameters $\theta_{i}(i=1,2,3)$.

Now, in order to prove the strongly uniformly practical stability (refer to Corollary 4.2) of (28), first let us prove the uniform practical stability. Suppose that $l\left(t_{0}\right) \leq \hbar_{1}$. Then, from (29) we have:

$$
\begin{aligned}
l(t) & \leq l\left(t_{0}\right)+r \\
& \leq \hbar_{1}+r \leq \hbar_{2}
\end{aligned}
$$

so that $l\left(t_{0}\right) \leq \hbar_{1}$ implies $l(t) \leq \hbar_{2}, \forall t \geq t_{0}$. According to (PS1), (28) is uniformly practically stable.

Next, let us prove the uniformly quasi-practical stability of (28). Suppose that there exist $\hbar_{1}>0, \Im>0$, $T>0, l\left(t_{0}\right) \leq \hbar_{1}$ and $t \geq t_{0}+T$. Equation (29) verifies the following inequality:

$$
\begin{aligned}
l(t) & \leq l\left(t_{0}\right) e^{-\delta T}+r \\
& \leq \hbar_{1} e^{-\delta T}+r \leq \Im
\end{aligned}
$$

so that $l\left(t_{0}\right) \leq \hbar_{1}$ implies $l(t) \leq \Im, \forall t \geq t_{0}+T$. According to (PS2), (28) is uniformly practically quasi-stable.

Then, according to definition (PS3), (28) is strongly uniformly practically stable.

In order to prove the strong uniform practical stability of (17), we check all the conditions of Theorem 4.1. It is clear that from (30) and (31), $\hbar_{1}<\hbar_{2}$, $\Im<\hbar_{2}$, then condition (i) of Theorem 4.1 is satisfied.

Now by using (18), we have $\eta^{\min }\|e\|^{2} \leq$ $V_{0}(t, e) \leq \eta^{\max }\|e\|^{2}, V_{0}(t, e)$ is a Lyapunov function, locally Lipschitz in $e$, where $\eta^{\mathrm{min}}=$ $\min \left\{\eta_{S_{i}}^{\min }, i=1,2,3\right\}$ and $\eta^{\max }=\max \left\{\eta_{S_{i}}^{\max }, i=1,2,3\right\}$. Taking $d_{1}(\|e\|)=\eta^{\min }\|e\|^{2}, \quad d_{2}(\|e\|)=\eta^{\max ^{2}}\|e\|^{2}$. Next, for $(t, e) \in \mathbb{R}_{+} \times B_{\hbar_{2}}, \quad d_{1}(\|e\|) \leq V_{0}(t, e) \leq d_{2}(\|e\|)$ and from (25) $\wp\left(t, V_{0}(t, e)\right)=-\delta V_{0}+\mu \psi \sqrt{V_{0}}$. Then, the conditions (ii) and (iii) of Theorem 4.1 are verified.

Next, we prove condition (iv) of Theorem 4.1. On one hand $v\left(t_{0}\right) \leq \hbar_{1}$ (because $\left.l\left(t_{0}\right) \leq \hbar_{1}\right)$ implies $v(t) \leq \hbar_{2}$ (because $\left.l(t) \leq \hbar_{2}\right), \forall t \geq t_{0}$. Moreover, $V_{0}(t, e)=\frac{1}{4} v(t)^{2}$. Then, it follows that $v\left(t_{0}\right) \leq \hbar_{1}$, implies $\eta^{\min }\left\|e_{0}\right\|^{2}<\frac{1}{4} \hbar_{1}^{2}$. Hence, $\left\|e_{0}\right\|<\frac{1}{2 \sqrt{\eta^{\min }}} \hbar_{1}$.

On the other hand, $\frac{1}{4} v(t)^{2}=V_{0}(t, e)=$ $\eta^{\max }\|e(t)\|^{2}<\frac{1}{4} \hbar_{2}^{2}$. Hence, $\|e(t)\|<\frac{1}{2 \sqrt{\eta^{\max }}} \hbar_{2}$. This proves the uniform practical stability of (17). Consequently $0<\frac{1}{2 \sqrt{\eta^{\min }}} \hbar_{1}<\frac{1}{2 \sqrt{\eta^{\max }}} \hbar_{2}$. Writing the above inequality in the following form, we have $\eta^{\max } \hbar_{1}^{2}<$ $\eta^{\min } \hbar_{2}^{2}$, that implies $d_{2}\left(\hbar_{1}\right)<d_{1}\left(\hbar_{2}\right)$. Finally, all 
conditions of Theorem 4.1 hold. Then, this implies the strongly uniformly practical stability of (17).

\section{Remark 4.4:}

(1) Inequality (26) depends on the Lipschitz constants. From Lipschitz constants, we can calculate the minimum value of $\theta_{i}(i=1,2,3)$. Then, we tune $\theta_{i}$ in order to precisely adjust the time convergence of the observer.

(2) In inequality (25), $\mu$ depends on parametric uncertainties (see $\mu_{6}$ and $\mu_{7}$ ). If IM parameters are exactly known $\mu=0$ otherwise (under uncertainties) $\mu \neq 0$. Then the precision of the observer depends on $\mu, \psi$ and $\delta$. The radius of the ball in the practical stability proof is $r=\frac{\psi \mu}{\delta}$. This radius can be adjusted by tuning $\delta\left(\theta_{i}\right)$.

\section{Experimental results}

The proposed observer algorithm has been tested using a $1.5 \mathrm{~kW}$ IM, whose data are reported in Tables 1 and 2 .

The experimental set-up is equipped with:

(1) Three phases inverter operated with a symmetrical PWM technique with $5 \mathrm{kHz}$ switching frequency.

(2) A permanent magnet synchronous motor controlled by industrial drive and used to provide a desired speed.

(3) A custom floating-point digital signal processor dSPACE (DS1103) board, and its interface. The dSPACE board performs data acquisition (two stator currents, DC-link voltage, load torque and rotor speed, by means of a $512 \mathrm{ppr}$ incremental encoder, and only for monitoring purposes), computes the control algorithm and

Table 1. Motor parameters values of the set-up.

\begin{tabular}{lc}
\hline Nominal rate power & $1.5 \mathrm{~kW}$ \\
Nominal angular speed & $1430 \mathrm{rpm}$ \\
Number of pole pairs & 2 \\
Nominal voltage & $220 \mathrm{~V}$ \\
Nominal current & $7.5 \mathrm{~A}$ \\
\hline
\end{tabular}

Table 2. Motor identified parameters.

\begin{tabular}{llcl}
\hline$R_{s}$ & $1.633 \Omega$ & $M_{s r}$ & $0.099 \mathrm{H}$ \\
$R_{r}$ & $0.93 \Omega$ & $J$ & $0.0111 \mathrm{Nm} \mathrm{sad}^{-1}$ \\
$L_{s}$ & $0.142 \mathrm{H}$ & $f_{v}$ & $0.0018 \mathrm{Nm} \mathrm{sad}^{-1}$ \\
$L_{r}$ & $0.076 \mathrm{H}$ & & \\
\hline
\end{tabular}

generates the PWM signals for the inverter actuation.

The algorithms implemented in the dSPACE board have a total time computational cost of $100 \mu \mathrm{s}$. The experimental sampling time $T$ is equal to $200 \mu \mathrm{s}$. The parameters were chosen as follows: $\alpha=0.01$, $k=0.012, \quad k_{c 1}=0.01, \quad k_{c 2}=0.01, \quad \varpi=5, \quad \theta_{1}=2000$, $\theta_{2}=3400$ and $\theta_{3}=2$ to satisfy convergence conditions.

The identified parameters of the IM have previously been obtained off-line and they are assumed to be close of the real values of the IM, it is clear that they are not exactly the real values. However, in the sequel these identified parameters are used to represent the so-called 'nominal system' and they will be used to start the test on the performance of the proposed observer.

The experimental results for 'the nominal case' (no uncertainties) are shown in Figure 1. These figures show that the estimated speed (Figure 1(a)) and the estimated load torque (Figure 1(d)) converge to their actual values (Figure 1(b)) and (Figure 1(c)), respectively. From this figure, we can see that the good performance of the observer under 'nominal' conditions. In this test, the initial value of the stator resistance is set equal to the identified value, and it is shown (Figure 1(e)) its convergence to a steady state value which is almost independent of the operating condition (observable and unobservable area). The convergence of the resistance estimator also reduces the speed observation error. From this figure, it follows that the estimated stator resistance rated value is constant. However, the behaviour of the observer is affected near and under conditions of unobservability. Comparing to the observer given in Ghanes et al. (2006), we noted that the estimated speed and load torque are not unstable near and under conditions of unobservability. However under these conditions, the asymptotically convergence of the errors dynamics is not ensured due to the inputs are not persistent in this zone. This is why we have introduced the practical stability.

The robustness of the observer is tested by introducing $+50 \%$ variation on rotor resistance value used in the observer parameters (Figure 2). This figure displays similar experimental results for the stator resistance nominal case under unobservability conditions. Comparing to 'nominal case' (Figure 1), it appears a static error between the estimated speed (Figure 2(b)) and measured speed (Figure 2(a)) when the motor is under conditions of observability.

A second robustness test is made now by introducing $-50 \%$ variation on rotor resistance value. The experimental results are shown in Figure 3. For the speed and load torque estimation, the conclusion is the same as $+50 \%$ variation case (Figure 2 ). 

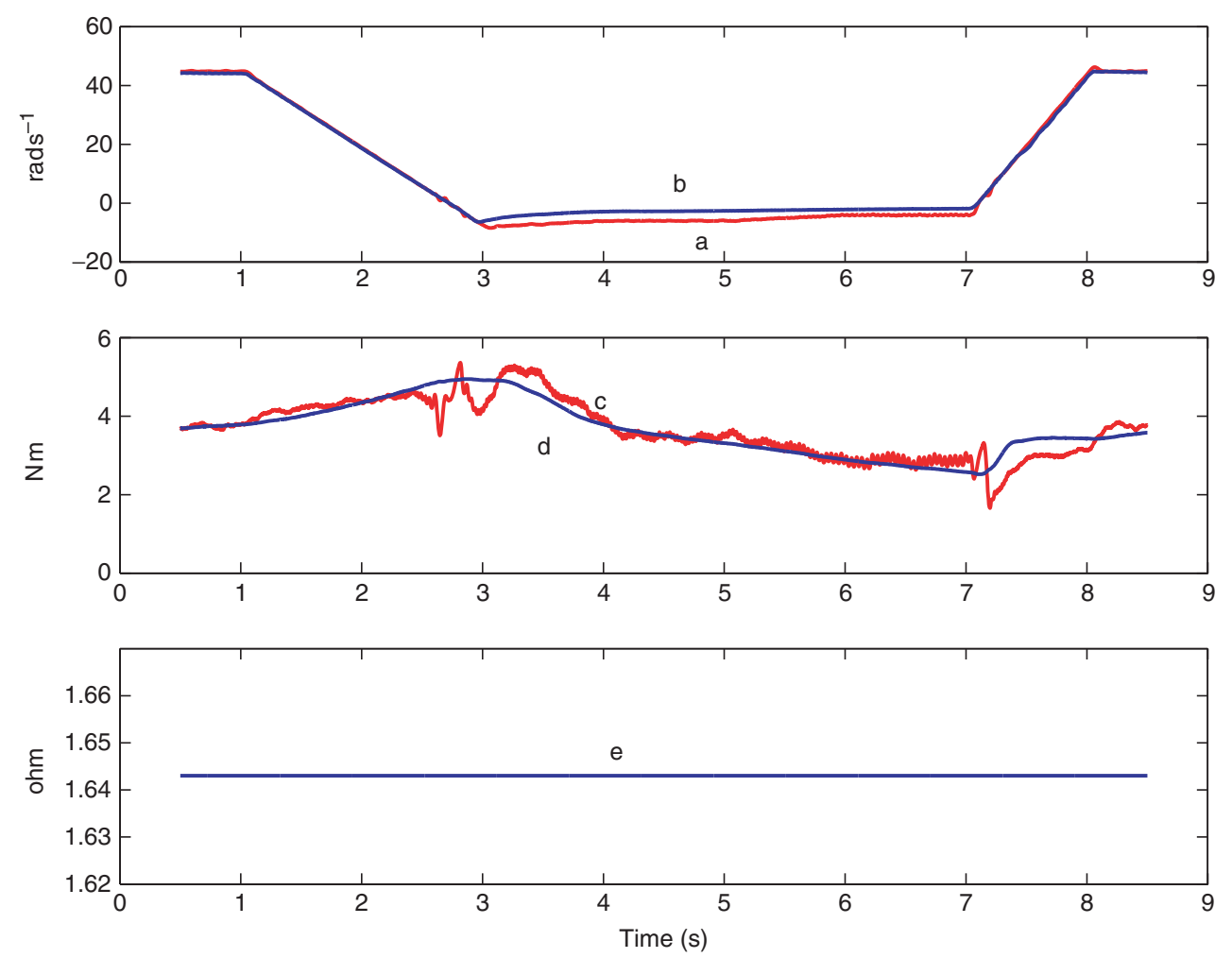

Figure 1. Nominal case. (a, c) measured speed $\left(\mathrm{rad} \mathrm{s}^{-1}\right)$ and load torque. $(\mathrm{Nm}),(\mathrm{b}, \mathrm{c}, \mathrm{e})$ estimation speed $\left(\mathrm{rad} \mathrm{s}^{-1}\right)$, load torque $(\mathrm{Nm})$ and stator resistance $(\mathrm{ohm})$.
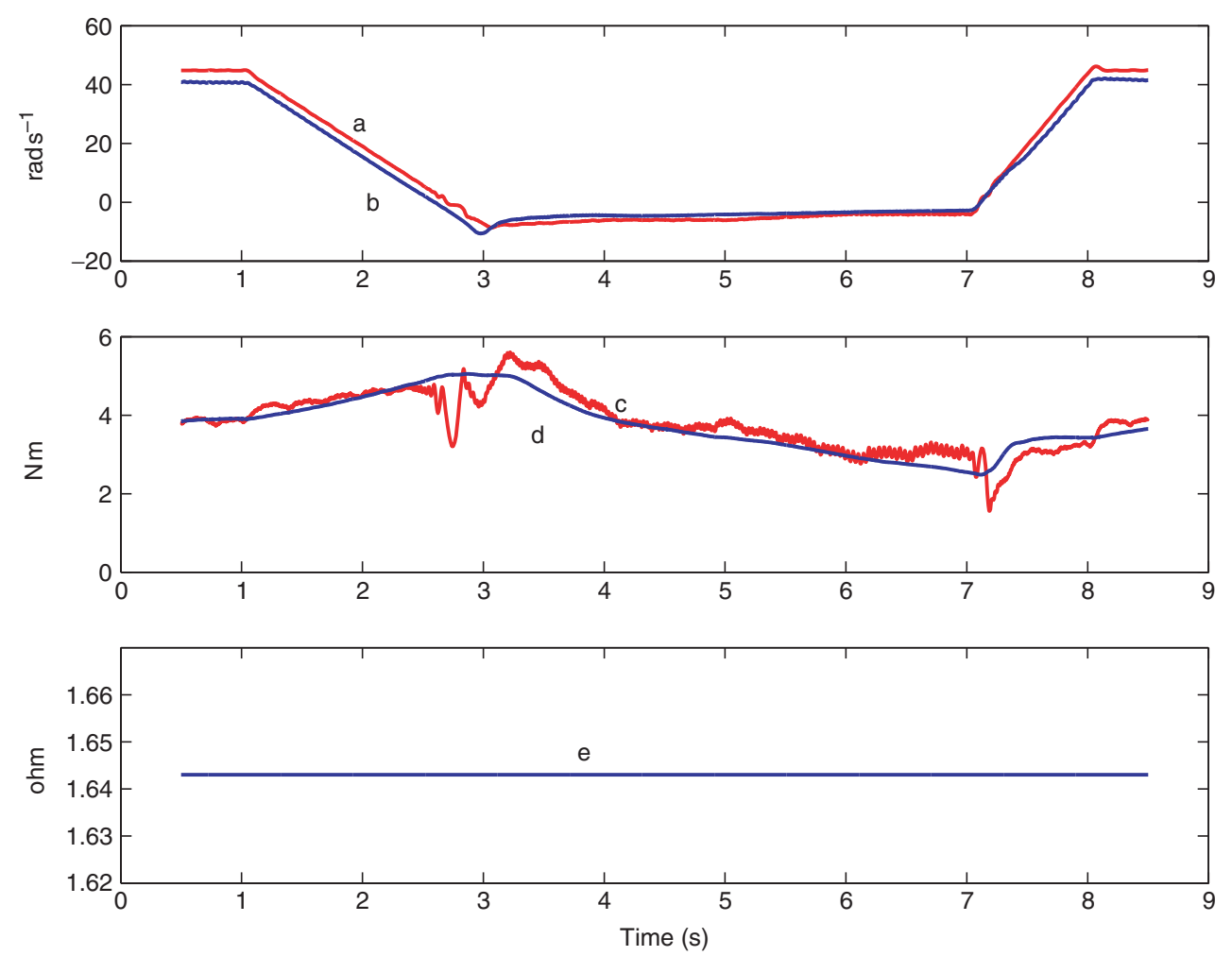

Figure 2. $+50 \%$ rotor resistance variation (refer to Figure 1 for details of a-e). 

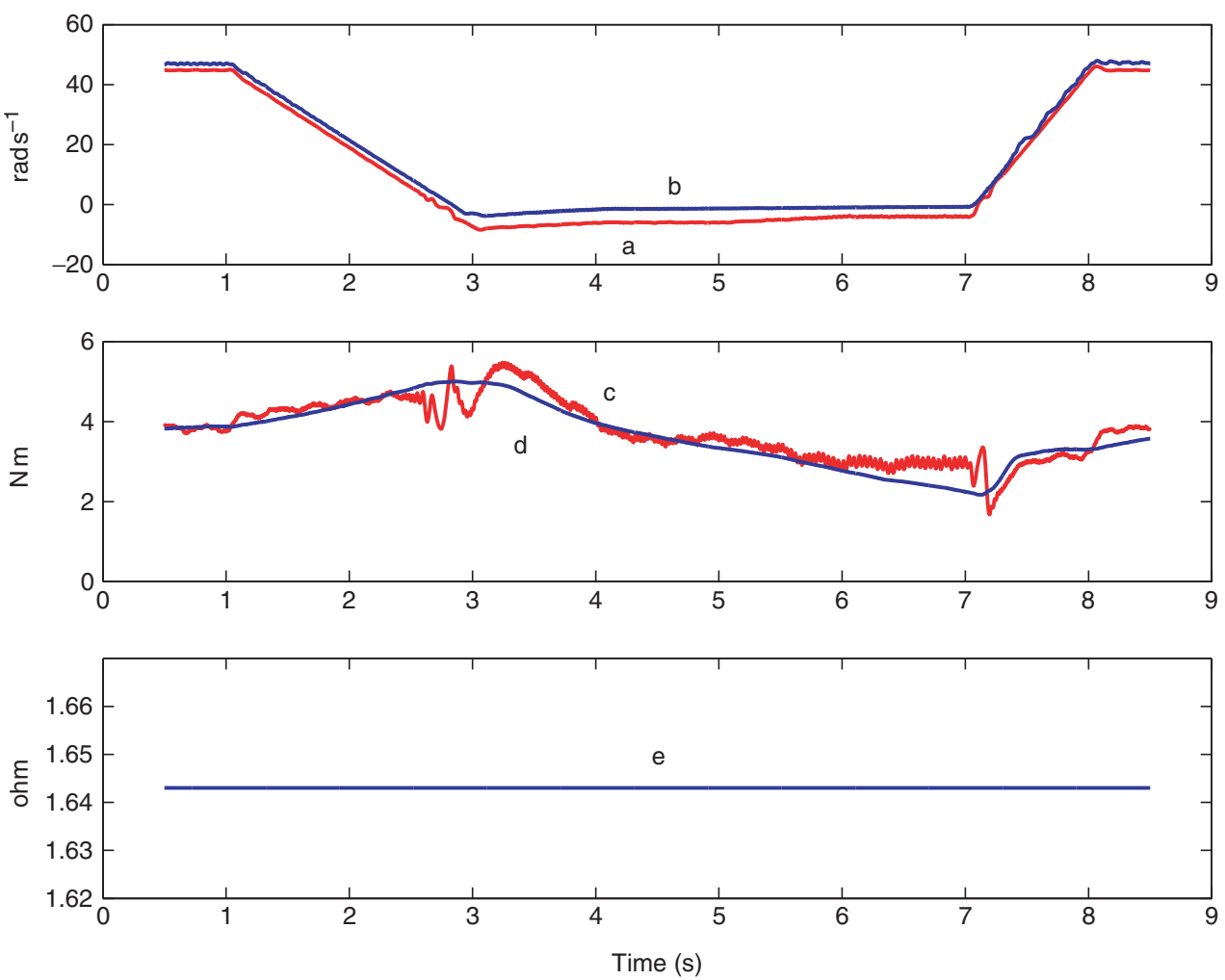

Figure 3. $-50 \%$ rotor resistance variation (refer to Figure 1 for details of a-e).
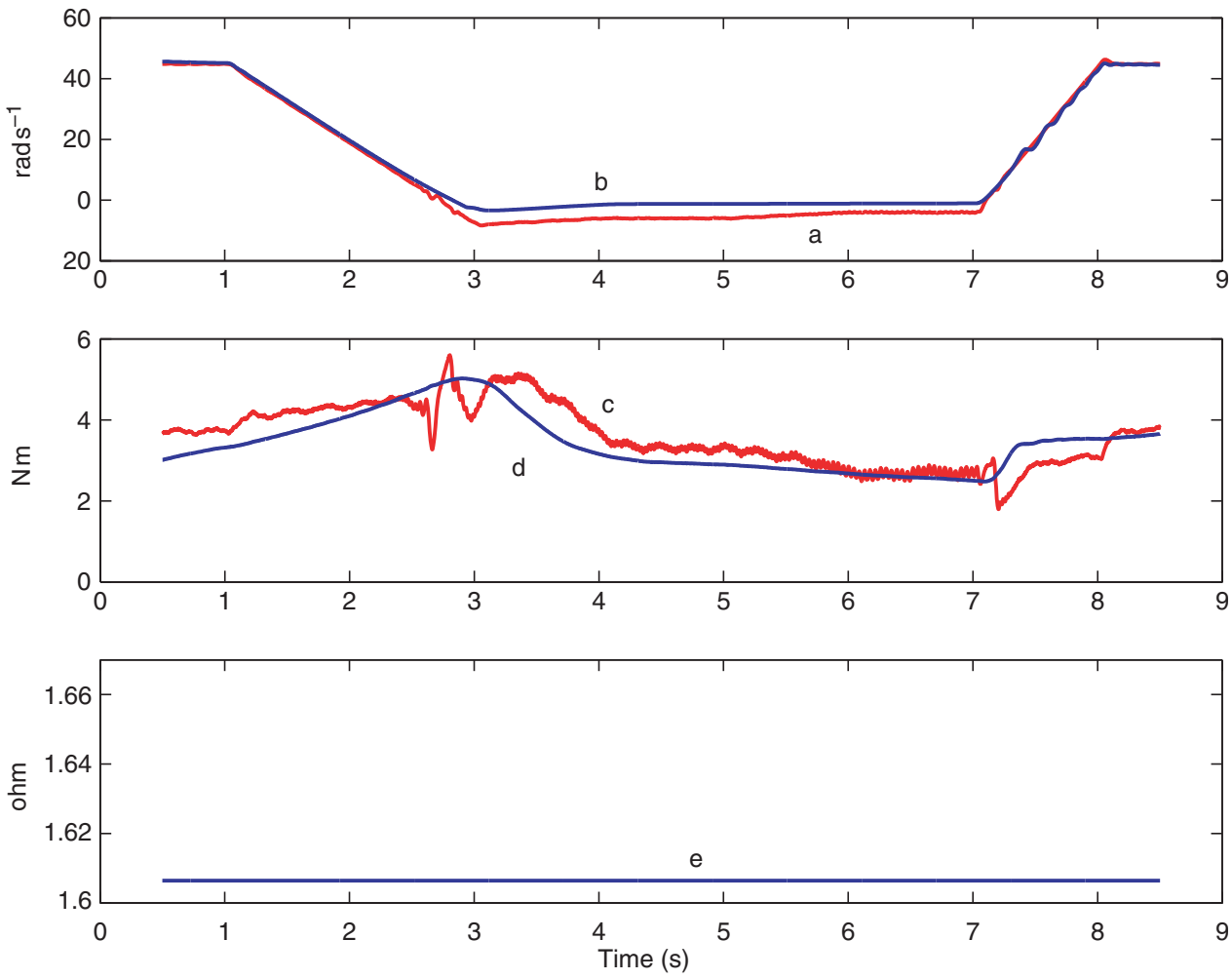

Figure 4. $-20 \%$ stator resistance initial value variation (refer to Figure 1 for details of a-e). 

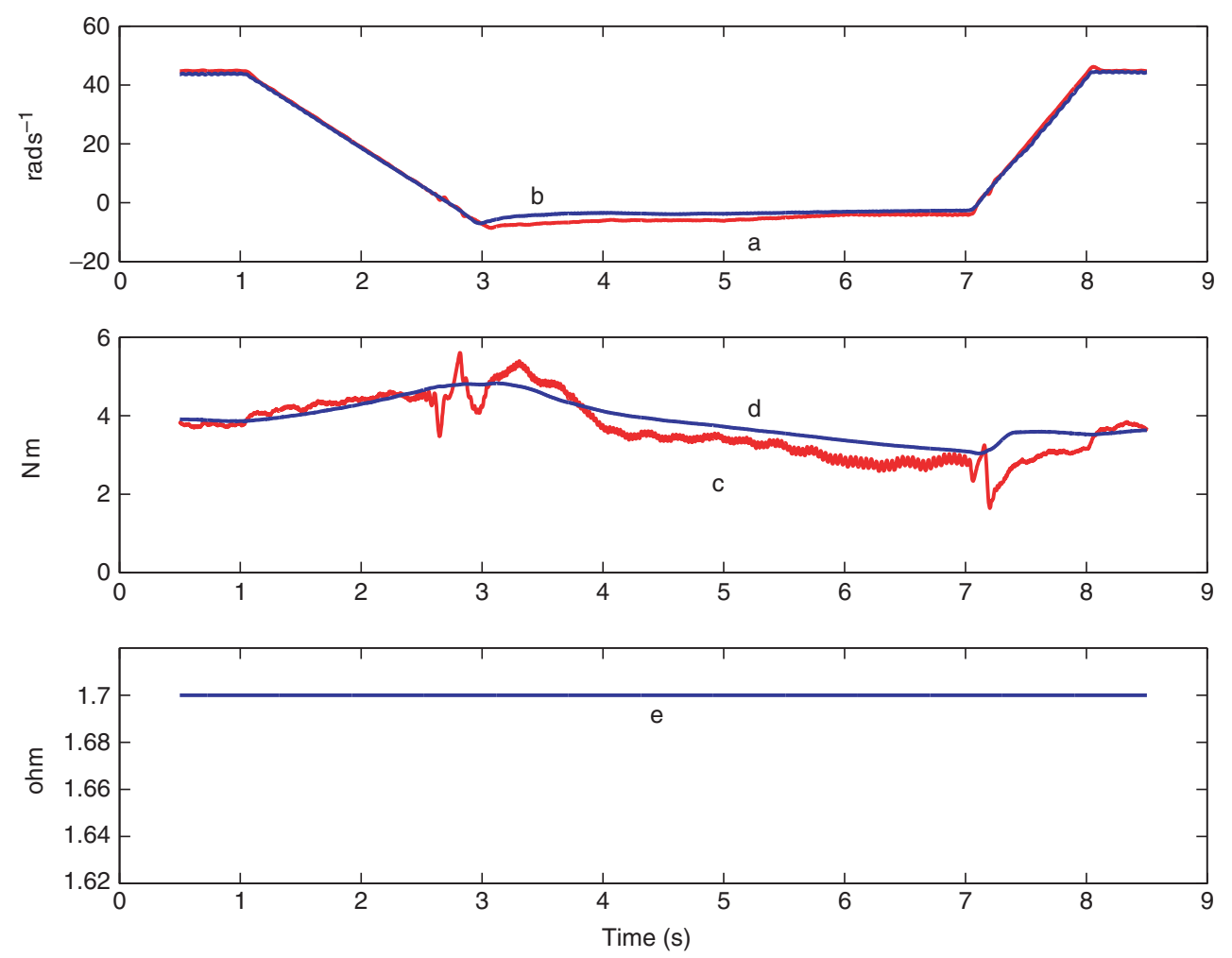

Figure 5. $+20 \%$ stator resistance initial value variation (refer to Figure 1 for details of a-e).
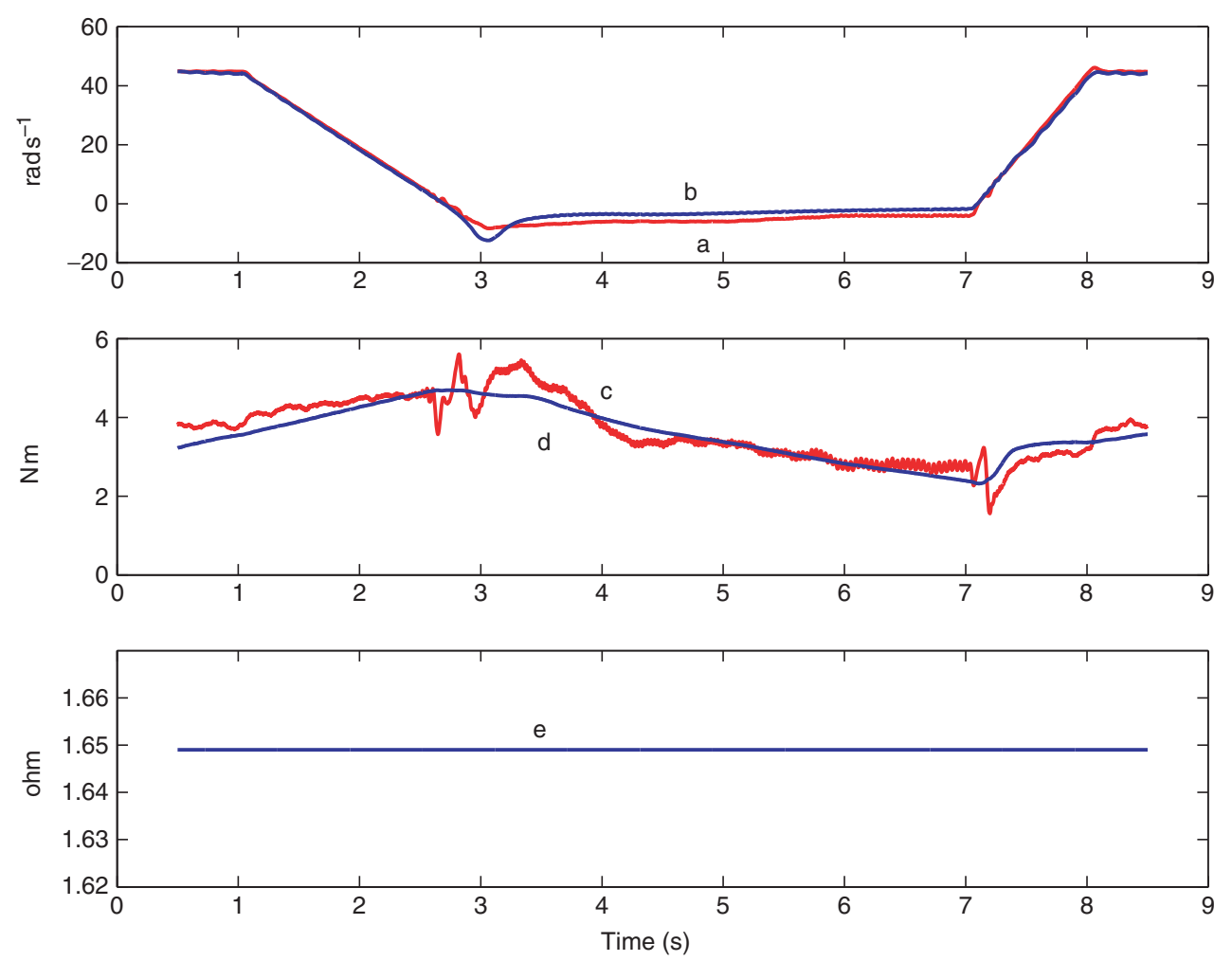

Figure $6 .+20 \%$ rotor self-inductance variation (refer to Figure 1 for details of a-e). 

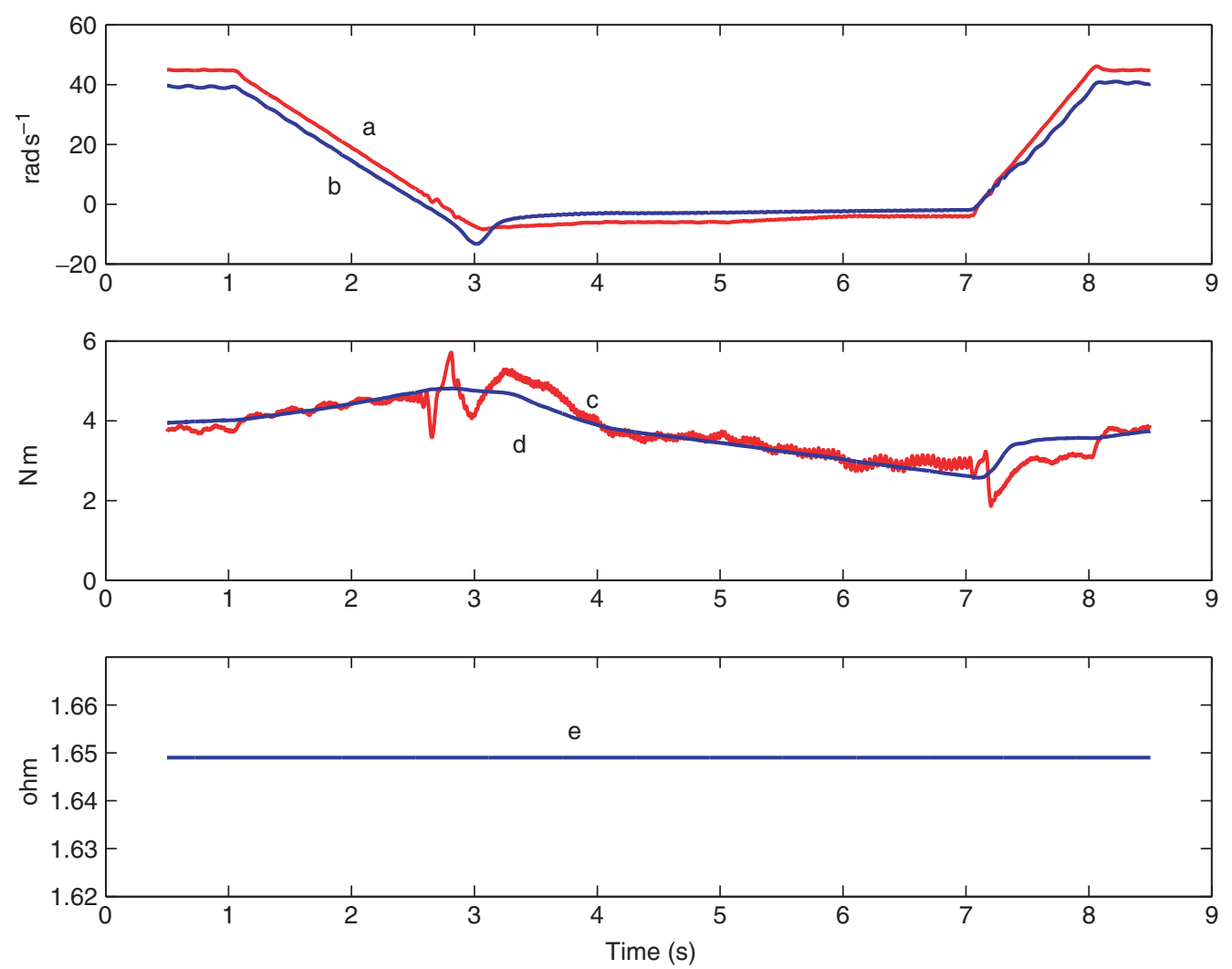

Figure 7. $+20 \%$ stator self-inductance variation (refer to Figure 1 for details of a-e).

The aim of the next test is to show the good performances at high speed (under observability conditions) and low speed (under unobservability conditions i.e. low-excitation frequency), when the observer is initialised by a wrong value of the stator resistance $\hat{R}_{s}$ (nominal value $\pm 20 \%$ ).

Figures 4 and 5 display an experimental result of this test with respectively $-20 \%$ and $+20 \%$ deviation for the stator resistance initial value. We conclude that the initialisation of the observer by the wrong value of stator resistance does not affect is performance. The estimated speed (Figures 4(a) and 5(a)) converges to the measured speed (Figures 4(b) and 5(b)). It is the same conclusion to the load torque; see respectively Figures 4(d) and 5(d) and Figures 4(c) and 5(c).

By comparing these results to the previous works (Ghanes et al. 2006; Traoré et al. 2006), we noted that the load torque is much better estimated. This is mainly due to the additional terms included in the proposed observer design and the better estimation of stator resistance rated value (Figures 4(e) and 5(e)).

A new test is made by introducing a variation of $+20 \%$ on rotor self-inductance and on stator selfinductance values. The results of these tests are shown in Figures 6 and 7, respectively. By analysing these figures, it can be noted that stator self-inductance variation affects more the performance of the adaptive observer than rotor self-inductance variation.

\section{Conclusion}

This study has investigated the observer design for IM drive without mechanical sensors (speed sensor, load torque sensor). The major contributions of this study are:

(1) The design of an adaptive interconnected observer that estimates the rotor speed, the rotor fluxes, the load torque and the stator resistance (critical parameter at low speed).

(2) Based on Lyapunov theory, sufficient conditions have been given to prove the properties of the practical stability of the error estimation dynamics are satisfied even under or near unobservability conditions.

(3) The successful application of the observer scheme on experimental set-up with a significant sensorless observer benchmark.

The experimental results confirm that the observer can be applied to reconstruct the state at low frequencies (near and under conditions of turning 
unobservability) without turning off the observer gains at low frequencies. Moreover, the robustness of the observer is verified by introducing significant parameter variations tests.

\section{Note}

1. For details about choice of reference frames (in the current case, dq-frame), see Chiasson (1995).

\section{References}

Barambones, O., and Garrido, A.J. (2004), 'A Sensorless Variable Structure Control for Induction Motor Drives', Electric Power Systems Research, 72, 21-24.

Besançon, G., and Hammouri, H. (1996), 'Observer Synthesis for Class of Nonlinear Control Systems', European Journal of Control, 2, 176-192.

Besançon, G., and Hammouri, H. (1998), 'On Observer Design for Interconnected Systems', Journal of Mathematical Systems, Estimation and Control, 8(3), 377-402.

Besançon, G., Leon, D.J., and Huerta, O. (2006), 'On Adaptive Observers for State Affine Systems', International Journal of Control, 79, 581-591.

Blaschke, F. (1972), 'The Principle of Field Orientation Applied to the New Transvector Closed-loop Control System for Rotating Field Machines', Siemens-Review, 39, 217-220.

Canudas, D.W.C., Youssef, A., Barbot, J.P., Martin, P., and Malrait, F. (2000), 'Observability Conditions of Induction Motors at Low Frequencies', in 39th IEEE Conference on Decision and Control, Australia, Vol. 3, pp. 2044-2049.

Chiasson, J. (1995), 'Non Linear Controllers For Induction Motors', in IFAC Conference System Structure and Control, France, pp. 572-583.

Furuhashi, T. (1990), 'A Position and Velocity Sensorless Control of Brushless DC Motors Using an Adaptive Sliding Observer', in IEEE 1990 Annual Meeting, pp. 1188-1192.

Ghanes, M., Huerta, O., Leon, D.J., and Glumineau, A. (2004), 'Validation of an Interconnected High Gain Observer for Sensorless Induction Motor on Low Frequencies Benchmark: Application to an Experimental Set-up', in 2nd IFAC Symposium on System, Structure and Control, Oaxaca, Mexico, pp. 365-370.

Ghanes, M., Leon, D.J., and Glumineau, A. (2005), 'Experimental Results of a Cascade Observer for Sensorless Induction Motor on Low Frequencies', in IFAC World Congress, Prague, Czech Republic.

Ghanes, M., Leon, D.J., and Glumineau, A. (2006), 'Observability Study and Observer-based Interconnected Form for Sensorless Induction Motor', in IEEE Conference on Decision \& Control, USA, pp. $1240-1245$.
Holtz, J. (2000), 'Is Sensorless Position Control of Standard Induction Motors a Feasible Technology', in Proceedings of the Power Electronics and Motion Conference, China, IPEMC, pp. 21-32.

Holtz, J. (2002), 'Sensorless Control of Induction Motor Drives', in Proceedings of the IEEE, Vol. 90, pp. 1359-1394.

Holtz, J., and Quan, J. (2002), 'Sensorless Vector Control of Induction Motors at Very Low Speed Using a Non-linear Inverter Model and Parameter Identification', IEEE Transactions on Industry Applications, 38, 1087-1095.

Ibarra, R.S., Moreno, J., and Espinosa, G. (2004), 'Global Observability Analysis of Sensorless Induction Motor', Automatica, 40, 1079-1085.

Jansen, P.L., and Lorenz, R.D. (1995), 'Transducer Less Position and Velocity Estimation in Induction and Salient AC Machines', IEEE Transactions on Industry Applications, 31, 240-247.

Kubota, H., Matsuse, K., and Nakano, T. (1993), 'DSP-Based Speed Adaptative Flux Observer of Induction Motor', IEEE Transactions on Industry Applications, 29, 344-348.

Laskhmikanthan, V., Leela, S., and Martynyuk, A.A. (eds.) (1990), Practical Stability of Non-linear Systems, World Scientific.

Marino, R. (1990), 'Adaptive Observers for Single Output Non-linear Systems', IEEE Transactions On Automatic Control, 35, 1054-1058.

Montanari, M., Peresada, S., and Tilli, A. (2003), 'Sensorless Indirect Field Oriented Control of Induction Motor Via Adaptive Speed Observer', in IEEE, Proceedings of American Control Conference, Colorado, Vol. 6, pp. 4675-4680.

Montanari, M., and Tilli, A. (2006), 'Sensorless Control of Induction Motors Based on High-Gain Speed Estimation and One-line Stator Resistance Adaptation', in The 32nd Annual Conference of IEEE Industrial Electronics Society, IECON, France, pp. 1263-1268.

Schreier, G., Leon, D.J., Glumineau, A., and Boisliveau, R. (2001), 'Cascade Nonlinear Observers: Application to an Experimental Induction Motor Benchmark', in IEE Proceeding - Control Theory and Applications, Vol. 148, pp. 509-515.

Takahashi, I., and Noguchi, T. (1986), 'A New Quick Response and High Efficiency Control Strategy of an Induction Motor', IEEE Transactions on Industry Applications, 22, 820-827.

Traoré, D., DeLeon, J., Glumineau, A., and Loron, L. (2006), 'Interconnected Observers for Sensorless Induction Motor in dq Frame: Experimental', in The 32nd Annual Conference of IEEE Industrial Electronics Society, IECON, France, pp. 5093-5100.

Tursini, M., Petrella, R., and Parasiliti, F. (2000), 'Adaptive Sliding Mode Observer for Speed Sensorless Control of Induction Motors', IEEE Transactions on Industry Applications, 36, 1380-1387.

Zhang, Q. (2002), 'Adaptive Observers for MIMO Linear Time-varying Systems', IEEE Transactions on Automatic Control, 47, 525-529. 